\title{
Novel Magnetic Zinc Oxide Nanotubes for Phenol Adsorption: Mechanism Modeling
}

\author{
Marwa F. Elkady 1,2,*, Hassan Shokry Hassan ${ }^{3, *}$, Wael A. Amer ${ }^{4}$, Eslam Salama ${ }^{5, *}$, \\ Hamed Algarni ${ }^{6,7}$ and Essam Ramadan Shaaban 8
}

1 Fabrication Technology Department, Advanced Technology and New Materials Researches Institute, City of Scientific Researches and technological applications, New Borg El-Arab City, Alexandria 21934, Egypt

2 Chemical and Petrochemical Engineering Department, Egypt-Japan University of Science and Technology, New Borg El-Arab City, Alexandria 21934, Egypt

3 Electronic Materials Researches Department, Advanced Technology and New Materials Researches Institute, City of Scientific Researches and technological applications, New Borg El-Arab City, Alexandria 21934, Egypt

4 Chemistry Department, Faculty of Science, Tanta University, Tanta 31527, Egypt; wael.amer@science.tanta.edu.eg

5 Environment and Natural Materials Research Institute (ENMRI), City of Scientific Research and Technological Applications, New Borg El-Arab City, Alexandria 21934, Egypt

6 Research Center for Advanced Materials Science (RCAMS), King Khalid University, Abha 61413, P.O. Box 9004, Saudi Arabia; halgarni@hotmail.com

7 Physics Department, Faculty of Science, King Khalid University, Abha 61413, P.O. Box 9004, Saudi Arabia

8 Physics Department, Faculty of Science, Al-Azhar University, Assiut 71452, Egypt; esam_ramadan2008@yahoo.com

* Correspondence: marwa.f.elkady@gmail.com (M.F.E.); hassan.shokry@gmail.com (H.S.H.); esalama@srtacity.sci.eg (E.S.); Tel.: +20-1005522825 (E.S.)

Received: 11 September 2017; Accepted: 15 November 2017; Published: 25 November 2017

\begin{abstract}
Considering the great impact of a material's surface area on adsorption processes, hollow nanotube magnetic zinc oxide with a favorable surface area of $78.39 \mathrm{~m}^{2} / \mathrm{g}$ was fabricated with the assistance of microwave technology in the presence of poly vinyl alcohol (PVA) as a stabilizing agent followed by sonic precipitation of magnetite nano-particles. Scanning electron microscopy (SEM) and transmission electron microscopy (TEM) micrographs identified the nanotubes' morphology in the synthesized material with an average aspect ratio of 3. X-ray diffraction (XRD) analysis verified the combination of magnetite material with the hexagonal wurtzite structure of $\mathrm{ZnO}$ in the prepared material. The immobilization of magnetite nanoparticles on to $\mathrm{ZnO}$ was confirmed using vibrating sample magnetometry (VSM). The sorption affinity of the synthesized magnetic $\mathrm{ZnO}$ nanotube for phenolic compounds from aqueous solutions was examined as a function of various processing factors. The degree of acidity of the phenolic solution has great influence on the phenol sorption process on to magnetic $\mathrm{ZnO}$. The calculated value of $\Delta \mathrm{H}^{0}$ designated the endothermic nature of the phenol uptake process on to the magnetic $\mathrm{ZnO}$ nanotubes. Mathematical modeling indicated a combination of physical and chemical adsorption mechanisms of phenolic compounds on to the fabricated magnetic $\mathrm{ZnO}$ nanotubes. The kinetic process correlated better with the second-order rate model compared to the first-order rate model. This result indicates the predominance of the chemical adsorption process of phenol on to magnetic $\mathrm{ZnO}$ nanotubes.
\end{abstract}

Keywords: magnetic nano-zinc oxide; nanotube structure; microwave technology; phenol uptake process 


\section{Introduction}

Nanotechnology has become one of the most active research areas in modern materials science. Generally, it is well known that the intrinsic properties of nanomaterials are inversely proportional to their size. So, whenever the nano-size of materials decreases, their exclusive properties such as catalysts, photoactivity, adsorptive and their various motivating features and applications will be enhanced [1]. The application of nanotechnology in water and wastewater treatment processes provides an innovative treatment capability and guaranteed economic results [2]. The nanomaterials are characterized by their effectiveness and a high capacity for decontaminating pollutants from wastewater compared to their larger counterpart materials. These characteristic features adapt their performance at water and wastewater treatment applications. Phenolic pollutants are considered priority pollutants in the water stream since they are harmful to organisms at low concentrations, can be toxic when present at elevated levels, and are known or suspected to be carcinogens. They are discharged mainly into environmental water from many industries, such as petroleum-refining, high-temperature coal conversion, resins and plastics. As they are highly harmful compounds, there is a necessity for phenol decontamination in industrial wastewater to preserve an environment that is clean and safe. Nowadays, different treatment processes are used for the removal and/or recovery of phenols such as hot gas or steam-stripping [3], adsorption [4], ion exchange [5], plasma oxidation [6], electrochemical [7], photo-catalysis [8] and biological treatment processes [9]. Among the different phenol decontamination techniques, the adsorption method represents the most appropriate technique for the removal of aromatic pollutants from contaminated wastewater compared with traditional utilized techniques such as electrochemical oxidation [10], coagulation, flocculation [11], photochemical destruction [12] and membrane filtration [13,14]. The adsorption capabilities of many nanomaterials and their composites such as nano-zeolites [15-18], nano-ion exchange materials [19-21] and nano-metal oxides [22] have been investigated extensively.

Recently, nano-metal oxides, especially $\mathrm{ZnO}$, have received considerable attention in the field of water remediation due to their unique structures and properties, such as the wide band gap in the near-ultraviolet (UV) spectral region, strong oxidation ability, and good photocatalytic property. The $\mathrm{ZnO}$ nanostructure is an environment-friendly material, as it is non-toxic for different organisms [23], which makes the material suitable for the treatment of water and wastewater. Besides, the photocatalytic capability of the $\mathrm{ZnO}$ nanostructure is similar to that of the $\mathrm{TiO}_{2}$ nanostructure because their band gap energies are almost the same [24]. However, the $\mathrm{ZnO}$ nanostructure has the advantage of low cost alongside its biocompatibility compared with the $\mathrm{TiO}_{2}$ nanostructure. So, various $\mathrm{ZnO}$ morphological nanostructures have been prepared such as nanoparticles (NPs), nanorods, nanowires, nanosheets, nanodumbbells, nanobelts, nanotubes, nanotetrapods and nanoflowers using various techniques [25]. Sol-gel, hydrothermal methods, electrochemical depositions, thermal deposition and combustion methods have been utilized to produce $\mathrm{ZnO}$ in various forms. Recently, microwave-assisted synthesis technology has been widely used not only to help in processing mono dispersed and highly homogeneous nanomaterials; but also for controlling the morphology of nanomaterials. So, the synthesis of ultrafine $\mathrm{ZnO}$ nanostructures with controlled morphology using microwave irradiation technology has been carried out in recent research [26] in order to produce $\mathrm{ZnO}$ in a specific morphological structure. This technique is considered to be a novel route to fabricating $\mathrm{ZnO}$ in a nanotube structure [21]. The nanotube structure possesses several different areas of contact (borders, inner and outer surfaces, and structured tube walls) that in principle can be functionalized in several ways. Moreover, the tubular nanostructures might exhibit some interesting physical and chemical properties unattainable in other nanostructures and open up possibilities for various new applications [27]. In spite of the interstitial properties of nanostructured $\mathrm{ZnO}$, the light absorption of $\mathrm{ZnO}$ nanomaterial as with $\mathrm{TiO}_{2}$ nanomaterial is limited due to their large band-gap energies [28]. Moreover, the handling of very fine $\mathrm{ZnO}$ nano-powdered material either in batch or continuous techniques in the water remediation process is very difficult [29]. In order to overcome all these limitations of $\mathrm{ZnO}$ nanomaterials, recently the synthesis of various nanocomposites, 
especially ferromagnetic nanocomposite materials, has become the most active subject in the field of nanomaterials.

One approach for producing ferromagnetic $\mathrm{ZnO}$ nanomaterials is to introduce small amounts of magnetic ions ( $\mathrm{Co}, \mathrm{Ni}, \mathrm{Fe}$ or $\mathrm{Mn}$ ) into the non-structured $\mathrm{ZnO}$, creating what is called diluted magnetic semiconductors (DMS). ZnO-based DMS have attracted a great deal of research attention and controversy over the past decade [28]. Although there are many papers reporting on ZnO-based DMS nanomaterials and their related applications, the main goals of this work differ. The basic idea of this research is to add magnetism to $\mathrm{ZnO}$ nanostructure material, keeping as many intrinsic properties of $\mathrm{ZnO}$ as possible [30]. This idea is implemented through the functionalization of the $\mathrm{ZnO}$ surface, by coupling it with iron oxide (magnetite) NPs. There is no need to utilize surfactants or organic ligands trapped at the interface, as previously described for the production of $\mathrm{Fe}_{3} \mathrm{O}_{4} / \mathrm{ZnO}$ core-shell magnetic nanoparticles [31]. On the contrary, it is important to keep surface fractions free from the two coupled metal oxides $\left(\mathrm{ZnO}\right.$ and $\left.\mathrm{Fe}_{3} \mathrm{O}_{4}\right)$ in the composite material as much as possible. These surface fractions of the coupled metal oxides will add new multifunctional properties. In recent research, the core-shell composite nanoparticles were utilized for the photo-degradation of organic dyes and phenols from polluted water [32]. However, the surface functionalization of $\mathrm{ZnO}$ nanostructure with iron oxide NPs has not been sufficiently investigated. Therefore, the aim of this work to focus mainly on the surface functionalization of prepared $\mathrm{ZnO}$ nanotubes with iron oxide $\left(\mathrm{Fe}_{3} \mathrm{O}_{4}\right) \mathrm{NPs}$ to produce magnetic $\mathrm{ZnO}$ composite nanotubes that can be utilized for phenol decontamination in polluted water. The physicochemical properties of prepared magnetic zinc oxide nanotubes were examined using various characterization techniques such as X-ray diffraction (XRD), scanning electron microscopy (SEM), transmission electron microscopy (TEM) and a vibrating sample magnetometer (VSM). The mechanism of the phenol sorption process on to synthetized magnetic zinc oxide nanotubes was investigated through equilibrium, kinetic and thermodynamic analysis of the experimental data.

\section{Materials and Methods}

\subsection{Synthesis of Magnetic Zinc Oxide Nanotubes}

Firstly, $\mathrm{ZnO}$ nanotube was prepared via microwave technique in presence of poly vinyl alcohol (PVA) as a stabilizing agent. Aqueous solution of zinc acetate $(14 \mathrm{mM}) \mathrm{Zn}\left(\mathrm{CH}_{3} \mathrm{COO}\right)_{2} \cdot 2 \mathrm{H}_{2} \mathrm{O}$ (Rankem, Gurgaon, India) was prepared by dissolving $8 \mathrm{~g}$ of zinc acetate in $150 \mathrm{~mL}$ of distilled water. Then, $25 \mathrm{mg}$ of PVA (Sigma-Aldrich, Darmstadt, Germany) was mixed with zinc salt as a stabilizing agent, and sodium hydroxide $(\mathrm{NaOH})$ (Sigma-Aldrich, Darmstadt, Germany) was added for zinc salt reduction. The prepared aqueous solution was maintained in a microwave (THOMSON-COMBI1, Thomson Premier Lighting \& Appliance, Logan, UT, USA) for $1 \mathrm{~h}$ at $800 \mathrm{~W}$. Subsequently, for magnetite immobilization, $0.5 \mathrm{~g}$ of the prepared nano-zinc oxide was suspended using a direct sonication probe ultrasonic homogenizer (Vibra-Cell VCX 500, SONICS, Newtown, CT, USA) in $200 \mathrm{~mL}$ mixed solution of iron (III) chloride and iron (II) sulphate with a molar ratio of 2:1 until homogeneous suspension was obtained. A sodium hydroxide solution of $5 \mathrm{M}$ was added dropwise to the previous suspension at $70{ }^{\circ} \mathrm{C}$ and maintained for $30 \mathrm{~min}$ under constant stirring until black precipitate of magnetic zinc oxide synthesised. The obtained black powders were washed several times with distilled water and absolute ethanol, and then separated using centrifugation at a force at $4000 \mathrm{rpm}$. Finally, the nanopowders were dried at $70{ }^{\circ} \mathrm{C}$ overnight.

\subsection{Characterization of Magnetic $\mathrm{ZnO}$ Nanotubes}

X-ray patterns of both $\mathrm{ZnO}$ before and after magnetite immobilization were determined using a (Schimadzu-7000, Shimadzu Corporation, Kyoto, Japan) diffractometer that was operated by $\mathrm{Cu} \mathrm{K} \alpha$ radiation $(\lambda=0.15406 \mathrm{~nm})$ produced at $30 \mathrm{kV}$ and $30 \mathrm{~mA}$. The prepared nanopowder materials were packed into a flat aluminum holder. The scan velocity was fixed at $2^{\circ} \cdot \mathrm{min}^{-1}$ from $10^{\circ}$ to $80^{\circ}$. 
The morphological structure of the prepared magnetic $\mathrm{ZnO}$ nanotubes was determined with scanning electron microscopy (JEOL JSM 6360LA, JEOL, Tokyo, Japan). The magnetic nanopowder material was stacked and gold sputtered over the aluminum holder to be examined. The scanning was carried out in order to recognize the morphological structure of the prepared material at different magnifications. The morphological structure of the synthesized composite was confirmed using a transmission electron microscope (TEM, JEM-2100, JEOL, Tokyo, Japan). The material's specific surface area, BET (Brunauer-Emmett-Teller), was measured using a nitrogen adsorption analyzer (Beckman Coulter SA3100, Brea, CA, USA).

The magnetic properties of the prepared magnetic material were analyzed using a vibrating sample magnetometer (VSM, Dexing, Model: 250, Lake Zurich, IL, USA) at room temperature.

Finally, the point of zero charge $\left(\mathrm{pH}_{\mathrm{pzc}}\right)$ of the prepared magnetic $\mathrm{ZnO}$ material was determined through mixing $0.15 \mathrm{~g}$ from the material with $50 \mathrm{~mL}$ of 0.1 molar $\mathrm{NaCl}$. The solution's $\mathrm{pH}$ was adjusted so that it could be maintained within the range 1-12 using $0.01 \mathrm{M} \mathrm{NaOH}$ and/or $0.01 \mathrm{M} \mathrm{HCl}$. Equilibration was realized by shaking in a thermostatic bath for $24 \mathrm{~h}$ at $25^{\circ} \mathrm{C}$. The dispersions were then separated and the final $\mathrm{pH}$ of the solutions was measured. The final solution $\mathrm{pH}$ was plotted against the initial $\mathrm{pH}$. The $\mathrm{pH}$ value at which the plotted curve intersects the line of $\mathrm{pH}$ (final) $=\mathrm{pH}$ (initial) was taken as the $\mathrm{pH}_{\mathrm{pzc}}$ of the prepared magnetic $\mathrm{ZnO}$ material surface.

\subsection{Batch Investigation of Magnetic Zinc Oxide Nanotubes}

The phenol adsorption capacity of the magnetic zinc oxide nanotubes was carried out by the batch contact method [24]. In batch method, $20 \mathrm{mg}$ of nano-zinc oxide were added to $10 \mathrm{~mL}$ of known phenol solution concentrations and mixed at different temperatures using a shaking incubator. The phenolic solution's $\mathrm{pH}$ was controlled with the addition of small quantities of $\mathrm{HCl}$ or $\mathrm{NaOH}(0.1 \mathrm{M})$. At the end of each batch test, the treated solution was centrifuged to determine the phenol concentration in the supernatant and measured using the colorimetry method with a UV spectrophotometer at 510 $\mathrm{nm}$. The percentage removal of phenol using magnetic zinc oxide adsorbent was estimated from Equation (1):

$$
\% \text { phenol removal }=\left(\left(C_{i}-C\right) / C_{i}\right) \times 100
$$

where $C_{i}$ is the initial phenol concentration in solution $(\mathrm{mg} / \mathrm{L})$; and $\mathrm{C}$ is the final phenol concentration in aqueous solution after phase separation $(\mathrm{mg} / \mathrm{L})$. The phenol uptake capacity was determined by calculating the uptake amounts per gram of magnetic zinc oxide from the following Equation (2):

$$
\mathrm{Q}(\mathrm{mg} / \mathrm{g})=\mathrm{V}\left(\mathrm{C}_{\mathrm{i}}-\mathrm{C}\right) / \mathrm{M}
$$

where $\mathrm{Q}$ is the phenol adsorption capacity $(\mathrm{mg} / \mathrm{g}) ; \mathrm{V}$ is the phenol volume $(\mathrm{mL})$; and $\mathrm{M}$ is the mass of magnetic zinc oxide nanotubes (g). The effect of the processing parameters' variation on the performance of phenol sorption on to the synthesized magnetic $\mathrm{ZnO}$ nanotubes was screened over the following studied ranges: contact time (0-180 min), solution $\mathrm{pH}(1-11)$, material dose (1-20 g/L), initial phenol concentration $(5-100 \mathrm{ppm})$ and solution temperature $\left(25-85^{\circ} \mathrm{C}\right)$. The accuracy and reliability of the collected data were confirmed by performing all adsorption experiments in triplicate, and the mean values were used in data analysis. The calculated relative standard deviations were found to be within $\pm 2 \%$.

\subsection{Kinetics and Thermodynamics Studies}

The thermodynamic parameters of the phenol adsorption process were evaluated to determine the nature of the process. The equilibrium behavior of the phenol sorption process on to magnetic $\mathrm{ZnO}$ nanotubes was examined using Langmiur, Frendlich and Temkin equilibrium isotherm equation models. The kinetics of the phenol sorption process were tested using the Pseduo-first-order, Pseduo-second-order and Elovich kinetic equation models. 


\section{Results and Discussion}

\subsection{Characterization of Hollow Structured Magnetic Zinc Oxide Nanotubes}

XRD patterns of both microwave-synthesized $\mathrm{ZnO}$ nanotubes and the magnetic composite material are investigated in Figure 1. The results indicate that both prepared materials have the same identical characteristic peaks. The main characteristic peaks of the hexagonal wurtzite $\mathrm{ZnO}$ structure are assigned at $2 \theta=31.74^{\circ}, 36.83^{\circ}$ and $47.62^{\circ}$, which correspond to (100), (101) and (102) planes. On the other hand, the main characteristic peaks of the immobilized magnetite on to the $\mathrm{ZnO}$ surface are assigned at $2 \theta=31.2^{\circ}, 35.9^{\circ}, 46.2^{\circ}, 57.4^{\circ}, 64.3^{\circ}$, which correspond to (220), (311), (400), (511) and (440) planes. So, the main characteristics peaks of $\mathrm{ZnO}$ at the magnetic $\mathrm{ZnO}$ match the main characteristic peaks of pure $\mathrm{ZnO}$ that show symmetry in XRD patterns of both pure $\mathrm{ZnO}$ and magnetic $\mathrm{ZnO}$ (Figure 1). The high-intensity degree of the peaks implies high materials crystallinity. It can be elucidated from Figure 1 that there are no characteristic peaks for impurities either in the pure $\mathrm{ZnO}$ or magnetic $\mathrm{ZnO}$ [19]. Accordingly, the prepared materials were pure materials without any contaminates from the PVA stabilizing agent.

The morphological structure of the synthesized magnetic zinc oxide is investigated in Figure 2. It is clear that, firstly, $\mathrm{ZnO}$ was prepared in a hollow nanotube structure. The nanotube formation may be due to the combination of microwave radiation in the presence of weak basic PVA surfactant material. The presence of PVA surfactant in the reaction media not only accelerates the reaction of the growth units, but also leads to their oriented growth by reducing the solution surface tension, which decreases the energy needed to form a new phase. The mechanism of $\mathrm{ZnO}$ nanotube formation in the microwave in the presence of PVA may be explained by the Kirkendall effect. In the Kirkendall effect, the diffusion of atoms causes oversaturation of lattice voids. It is considered that this oversaturation causes condensation of more voids close to the interface. Therefore, these Kirkendall voids change the properties of the interface and force it to form hollow nanotubes after ageing time of $1 \mathrm{~h}$ [33].

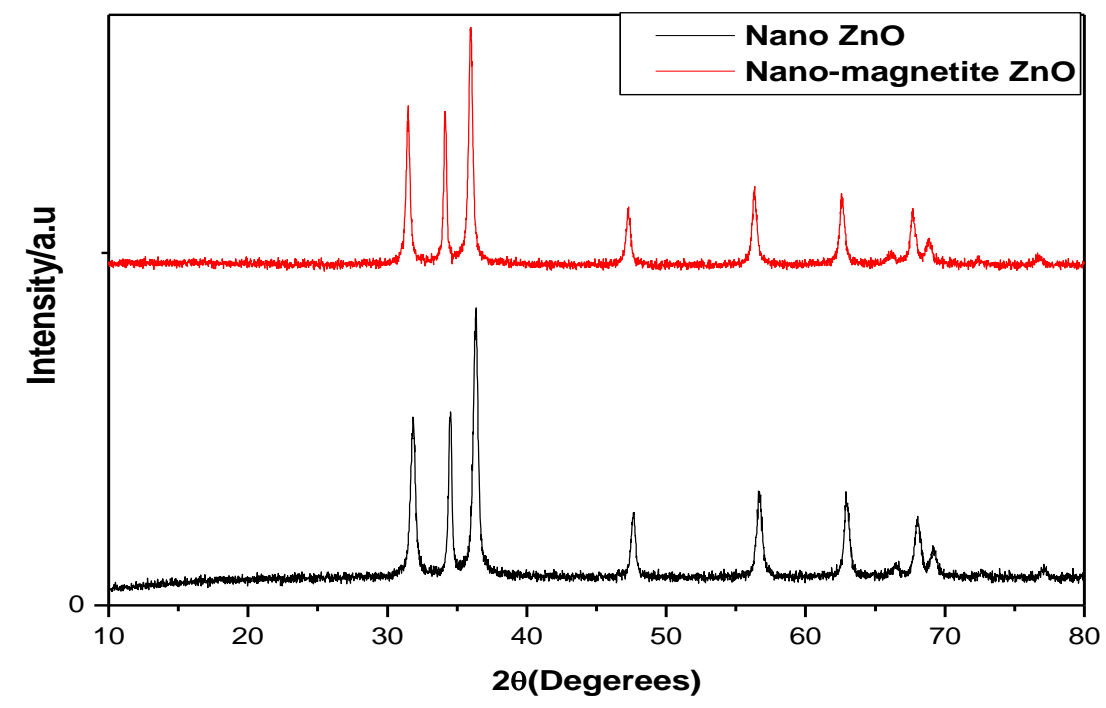

Figure 1. X-ray diffraction (XRD) patterns for pure $\mathrm{ZnO}$ nanotubes and magnetic $\mathrm{ZnO}$ nanotubes.

TEM analysis was applied to study the detailed structural features of magnetic nano-zinc oxide at Figure 3. The TEM image of magnetic $\mathrm{ZnO}$ nanotubes reveals that the $\mathrm{Fe}_{3} \mathrm{O}_{4}$ nanoparticles are uniformly distributed on the plane of $\mathrm{ZnO}$ nanotube surfaces and the magnetite particles successfully wrap around the surface of the $\mathrm{ZnO}$.

The magnetic properties of the magnetic zinc oxide nanotubes have been investigated using a vibrating sample magnetometer at room temperature, as shown in Figure 4. The hysteresis loop of the synthesized magnetic zinc oxide nanotubes is recorded in Figure 4. It is clear that the material is 
a typical superparamagnetic. The saturation moment per unit mass, Ms, for the magnetic nano-zinc oxide is $12.0052 \mathrm{emu} / \mathrm{g}$. These properties are assigned to the immobilized magnetite nanoparticles on to zinc oxide nanotubes. The results agree with a previous study, that magnetite nanoparticles exhibit superparamagnetic properties when they are smaller than the critical size of the magnetic domain size [34].

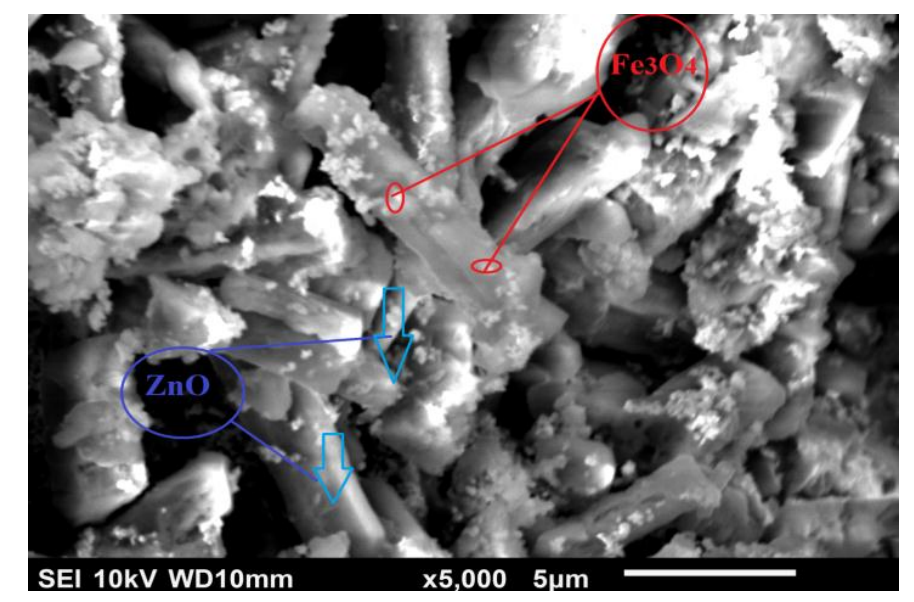

Figure 2. Scanning electron microscopy (SEM) images of the magnetic $\mathrm{ZnO}$ nanotubes.

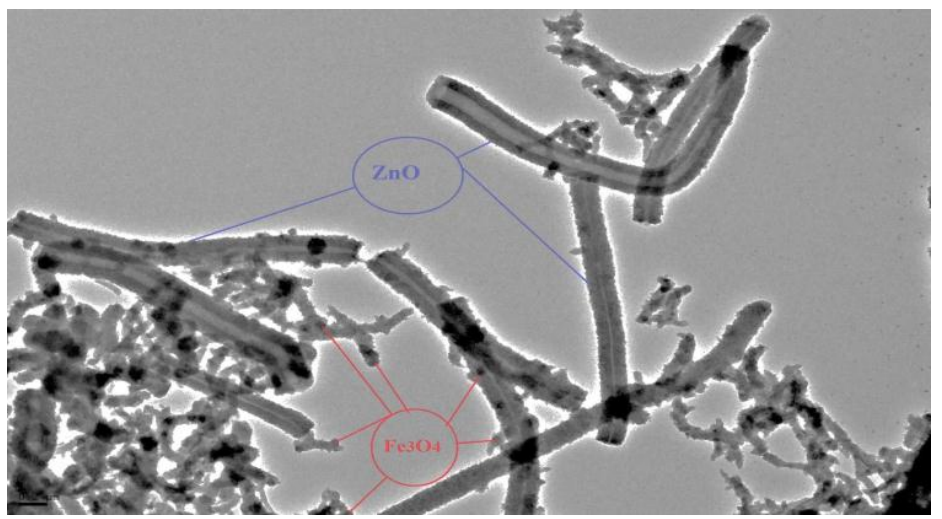

Figure 3. Transmission electron microscopy (TEM) images of the magnetic $\mathrm{ZnO}$ nanotubes.

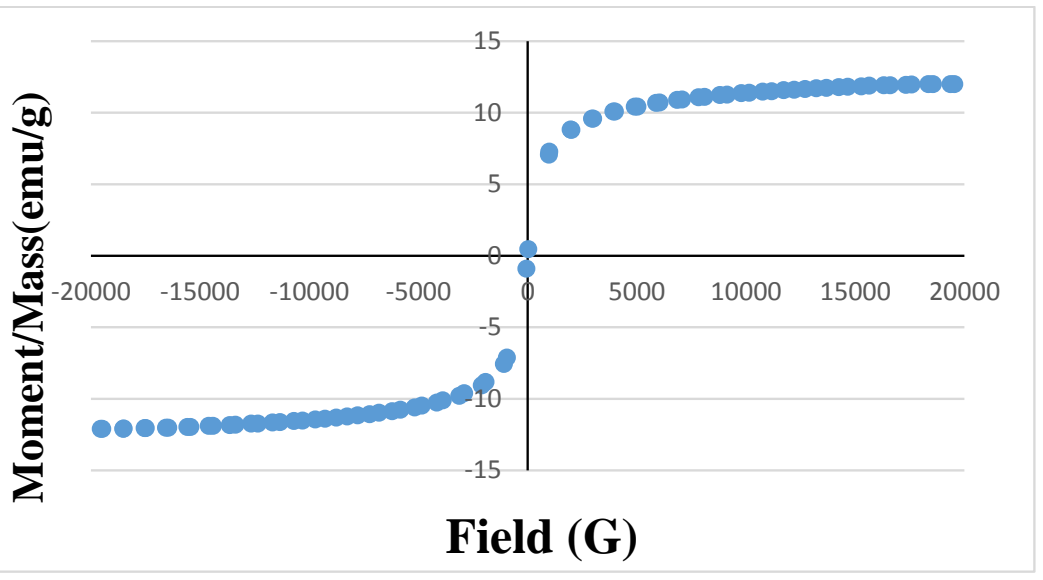

Figure 4. Magnetization curves of magnetic $\mathrm{ZnO}$ nanotubes. 


\subsection{Magnetic Zinc Oxide Nanotubes for Phenol Removal}

The feasibility of the synthesized magnetic zinc oxide nanotubes for phenol sorption from synthetic wastewater was examined.

\subsubsection{Influence of Contact Time on the Phenol Sorption Process on to Magnetic ZnO Nanotubes}

The influence of contact time on the adsorption of the phenol on to magnetic zinc oxide nanotubes was investigated at up to $180 \mathrm{~min}$ time intervals. From Figure 5, it is clear that in the initial period, the phenol adsorption on to the magnetic material is a rapid process that then decreases with time until reaching the equilibrium state. The fast adsorption of phenol relates to the high available surface area of the prepared magnetic $\mathrm{ZnO}$ nanotubes that equal $51.45 \mathrm{~m}^{2} / \mathrm{g}$. The quantity of phenol ions adsorbed on to the magnetic nanomaterial is at dynamic equilibrium with phenol ions desorbed from the material [35]. The equilibrium time of the phenol sorption process is recorded within $90 \mathrm{~min}$, with maximum phenol percentage removal of $87.75 \%$ under these particular conditions.

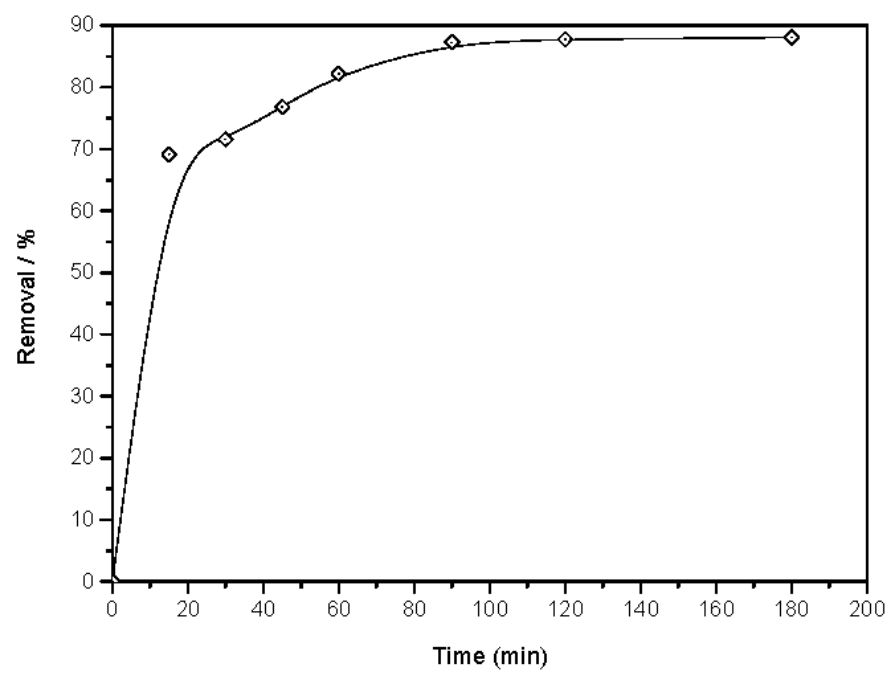

Figure 5. Influence of contact time on phenol sorption process on to magnetic $\mathrm{ZnO}$ nanotubes $(\mathrm{pH}=5$, initial phenol concentration $=10 \mathrm{ppm}$, agitation speed $=440 \mathrm{rpm}$, material dosage $=2 \mathrm{~g} / \mathrm{L}$ and temperature $=25^{\circ} \mathrm{C}$ ).

\subsubsection{Influence of Magnetic Nano-ZnO Dosage on the Phenol Adsorption Process}

Adsorbent dosage represents an important parameter due to its strong effect on the capacity of an adsorbent at a given initial concentration of the adsorbate [36]. The influence of magnetic $\mathrm{ZnO}$ nanotube dosage on both percentage phenol removal and material sorption capacity was traced after $90 \mathrm{~min}$. Figure 6 reveals that the phenol removal percentage is enhanced from 81.54 to $95.59 \%$ as magnetic $\mathrm{ZnO}$ nanotubes dosages improved from 1 to $20 \mathrm{~g} / \mathrm{L}$, and a decrease of the particles sorption capacity is noticed with increasing material dosage. The decline at unit adsorption with increasing particle concentration may be due to the remaining of unsaturated adsorption sites on the magnetic $\mathrm{ZnO}$ adsorbent material [37]. However, the increase in the magnetic $\mathrm{ZnO}$ nanotube dosage increases the availability of more active sites available for the phenol adsorption process. These results may be owing to the large determined active surface area of the prepared hollow-structured magnetic $\mathrm{ZnO}$ which is the equivalent $51.45 \mathrm{~m}^{2} / \mathrm{g}$. 


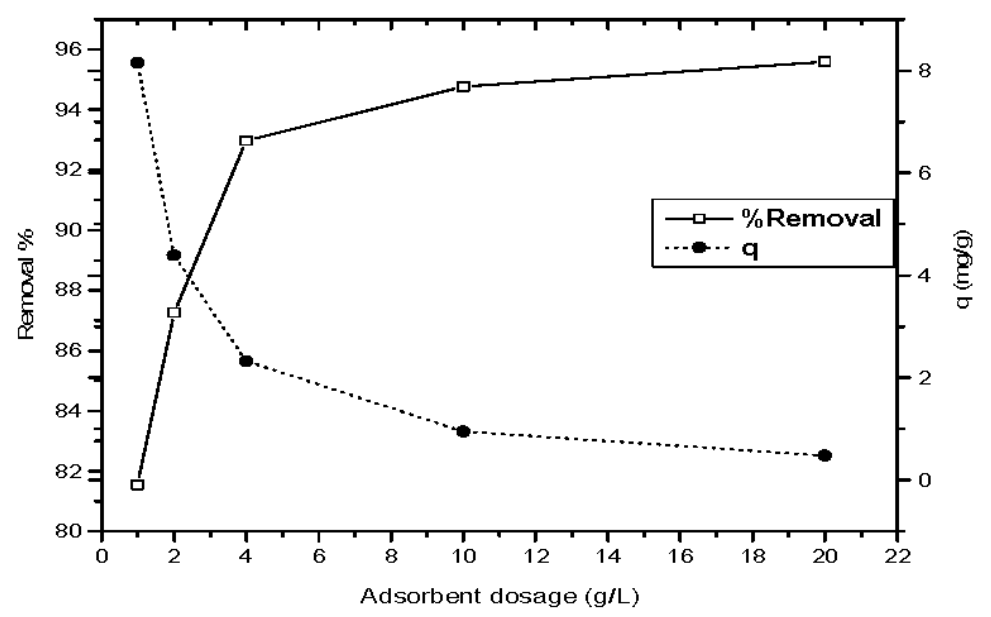

Figure 6. Influence of magnetic $\mathrm{ZnO}$ nanotubes dosage on both phenol percentage removal and phenol uptake capacity $(\mathrm{pH}=5$, initial phenol concentration $=10 \mathrm{ppm}$, agitation speed $=440 \mathrm{rpm}$, contact time $=90 \mathrm{~min}$ and temperature $=25^{\circ} \mathrm{C}$ ).

It obvious from Figure 6 that the optimum $\mathrm{ZnO}$ dosage is recorded as $2.5 \mathrm{~g} / \mathrm{L}$ at the line's intersection between the phenol percentage removal and material adsorption capacity. However, the $\mathrm{ZnO}$ dosage of $2 \mathrm{~g} / \mathrm{L}$ studied represents the closed economical dosage to the recorded value of the lines' intersection. So, the optimum magnetic $\mathrm{ZnO}$ dosage that achieved the optimum phenol removal percentage of $87.75 \%$ and adsorption capacity of $3 \mathrm{mg} / \mathrm{g}$ is considered to be $2 \mathrm{~g} / \mathrm{L}$.

\subsubsection{Influence of Initial $\mathrm{pH}$ on the Phenol Adsorption Process}

The solution's $\mathrm{pH}$ has a significant impact on control of the phenol adsorption process on to magnetic $\mathrm{ZnO}$ nanotubes, affecting the surface charge of the adsorbent material as well as the degree of ionization of phenol considerably [36]. It can be observed from Figure 7, that the adsorption is high at lower $\mathrm{pH}$, meaning the magnetic $\mathrm{ZnO}$ has greater adsorption capacity in an acidic medium. The adsorption percentage of phenol is high at $\mathrm{pH}=5$ and gradually decreases with increasing $\mathrm{pH}$ of the solutions; the lowest adsorption is observed at $\mathrm{pH}=11$. The vital factor for phenol adsorption on to the prepared material is the $\mathrm{pH}_{\mathrm{pzc}}$ of magnetic $\mathrm{ZnO}$. The point zero charge (pzc) of the prepared magnetic $\mathrm{ZnO}$ was recorded experimentally to be around 6 (figure not included). So, at any $\mathrm{pH}$ below the pzc, the surface of the magnetic $\mathrm{ZnO}$ material is positively charged; and above the pzc, it is negatively charged. The optimum adsorption of phenol on to the magnetic material was recorded at $\mathrm{pH}=5$. This result can be attributed to both the phenol ionization capacity and point zero charge $\left(\mathrm{pH}_{\mathrm{pzc}}\right)$ of magnetic $\mathrm{ZnO}$. As the $\mathrm{pH}$ of the solution increases, the percentage of unionized species of phenol decreases and the ionized species increases. This is due to the fact that the $\mathrm{pKa}$ value of phenol is $\sim 9.8$ [37]. At solution $\mathrm{pH}=5\left(\mathrm{pH} 5<\mathrm{pH}_{\mathrm{pzc}}\right)$, the magnetic $\mathrm{ZnO}$ surface is positively charged, so there is no electrostatic repulsion between the unionized phenol species and the positively charged surface that increases the adsorption process. However, as the solution $\mathrm{pH}$ increases $\left(\mathrm{pH} 7>\mathrm{pH}_{\mathrm{pzc}}\right)$, the adsorbent surface is negatively charged, reducing phenol adsorption due to the repulsive force between the phenolate ion and the negative charge of the magnetic $\mathrm{ZnO}$ surface [38]. 


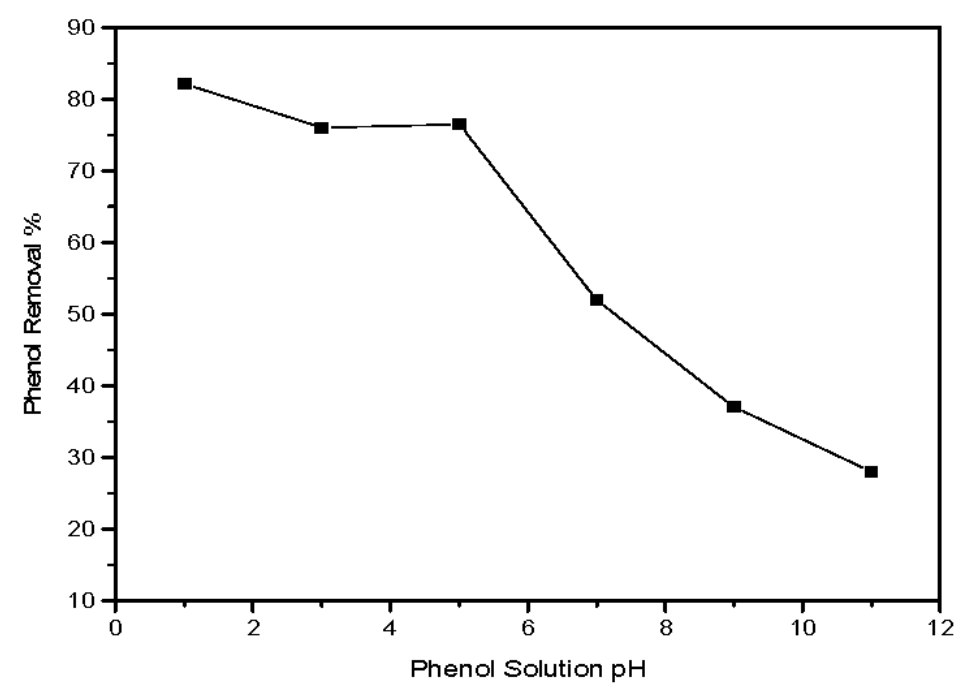

Figure 7. Influence of solution $\mathrm{pH}$ on the percentage of phenol removal on to magnetic $\mathrm{ZnO}$ nanotubes (initial phenol concentration $=10 \mathrm{ppm}$, material dosage $=2 \mathrm{~g} / \mathrm{L}$, agitation speed $=440 \mathrm{rpm}$, contact time $=90 \mathrm{~min}$ and temperature $=25^{\circ} \mathrm{C}$ ).

\subsubsection{Influence of Initial Phenol Concentration on the Adsorption Process}

The influence of initial phenol concentration on the phenol sorption capacity (q) at equilibrium was carried out in the range of 5-100 $\mathrm{mg} / \mathrm{L}$ at a $\mathrm{pH}$ value of 5 using $2 \mathrm{~g} / \mathrm{L}$ of magnetic $\mathrm{ZnO}$ nanotubes for $90 \mathrm{~min}$. Figure 8 shows that there is an enhancement in the phenol sorption capacity as the initial concentration of the phenol increases from 5-100 mg/L, which is in accordance with other reported research [30]. This behavior may be attributed to the saturation of the adsorption sites on the magnetic $\mathrm{ZnO}$ nanotubes as the concentration of the phenol increases. According to these results, the fabricated magnetic zinc oxide nanotubes are effectively capable of removing the phenol from solutions with a variable initial concentration range completely.

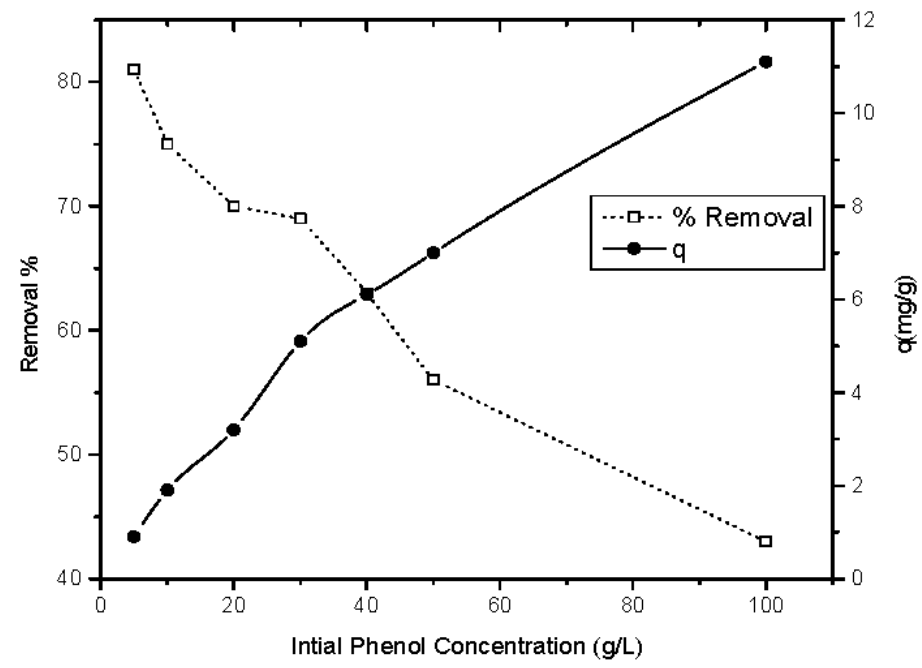

Figure 8. Influence of initial phenol concentration on both the percentage of phenol removal and phenol uptake capacity on to magnetic $\mathrm{ZnO}$ nanotubes $(\mathrm{pH}=5$, material dosage $=2 \mathrm{~g} / \mathrm{L}$, agitation speed $=440 \mathrm{rpm}$, contact time $=90 \mathrm{~min}$ and temperature $=25^{\circ} \mathrm{C}$ ). 


\subsubsection{Influence of Solution Temperature on the Phenol Adsorption Process}

Figure 9 elucidates the impact of the phenol solution's temperature $\left(25-85^{\circ} \mathrm{C}\right)$ on the percentage of phenol removal on to the synthesized magnetic $\mathrm{ZnO}$ nanopowder. Moreover, this figure indicates that rising temperature enhances the phenol decontamination process. This behavior may be owing to the chemical interaction between phenol and magnetic $\mathrm{ZnO}$ material. Moreover, the rate of intraparticle diffusion of phenols into the pores of the magnetic adsorbent is enhanced, and that may create new reaction sites on to the magnetic $\mathrm{ZnO}$ at high solution temperature [39]. These results indicate that phenol sorption is an endothermic process.

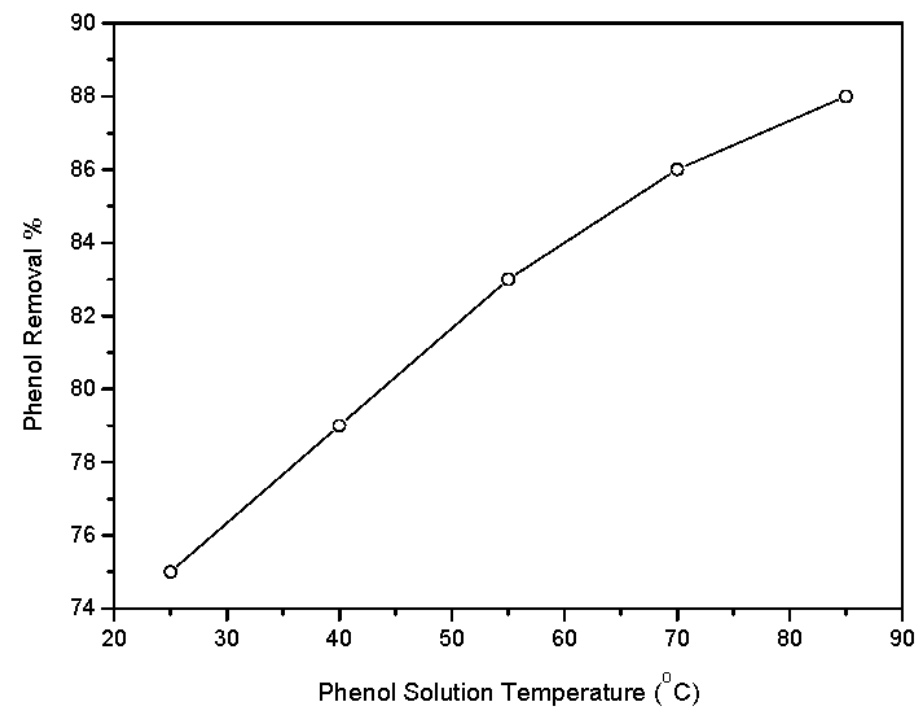

Figure 9. Influence of phenol solution temperature on the percentage of phenol removal on to magnetic $\mathrm{ZnO}$ nanotubes (initial phenol concentration $=10 \mathrm{ppm}$, material dosage $=4 \mathrm{~g} / \mathrm{L}$, agitation speed $=440 \mathrm{rpm}$, contact time $=90 \mathrm{~min}$ and $\mathrm{pH}=5$ ).

\subsection{Thermodynamics and Equilbrium Modeling}

Temperature dependence of the phenol adsorption process on to hollow-structured magnetic $\mathrm{ZnO}$ nanotubes is associated with various thermodynamic parameters, where the standard Gibbs free energy of the process is evaluated from Equation (3) [38]:

$$
\Delta \mathrm{G}^{0}=-\mathrm{RT} \ln \mathrm{k}_{\mathrm{c}}
$$

The equilibrium constant $\mathrm{k}_{\mathrm{c}}$ is estimated at each phenol solution temperature as indicated in Equation (4):

$$
\mathrm{k}_{\mathrm{c}}=\frac{\mathrm{C}_{\mathrm{Be}}}{\mathrm{C}_{\mathrm{Ae}}}
$$

where $\mathrm{C}_{\mathrm{Be}}$ and $\mathrm{C}_{\mathrm{Ae}}$ represent the equilibrium concentrations of phenol on magnetic $\mathrm{ZnO}$ adsorbent and solution, respectively. Standard enthalpy $\left(\Delta \mathrm{H}^{0}\right)$ and entropy $\left(\Delta \mathrm{S}^{0}\right)$ are calculated from the Van't Hoff Equation (5):

$$
\operatorname{lnk}_{\mathrm{c}}=\frac{\Delta \mathrm{S}^{0}}{\mathrm{R}}-\frac{\Delta \mathrm{H}^{0}}{\mathrm{RT}}
$$

Activation Energy $\left(E_{a}\right)$ is determined from the solution reaction relationship between $E_{a}$ and $\Delta \mathrm{H}^{0}[24]$ :

$$
\mathrm{E}_{\mathrm{a}}=\Delta \mathrm{H}^{0}+\mathrm{RT}
$$

$\Delta \mathrm{H}^{0}$ and $\Delta \mathrm{S}^{0}$ are obtained from the slope and intercept of the plot of $\ln \mathrm{K}_{\mathrm{c}}$ against $1000 / \mathrm{T}$ and the data are tabulated in Table 1 . The calculated values of free energy changes $\Delta G^{0}$ have negative 
charges that allow prediction about the spontaneous and thermodynamically favorable nature of the phenol adsorption process on to magnetic $\mathrm{ZnO}$. The negative values of the $\Delta \mathrm{G}^{0}$ depression with the rise in temperature increase the driving force of the adsorption process. Therefore, the enhancement in temperature has a positive impact on the sorption process of phenol. The positive value of $\Delta \mathrm{H}^{0}$ designates that the adsorption process is endothermic in nature. The positive value of entropy change $\left(\Delta S^{0}\right)$ shows an increase in disorder at the solid/liquid interface through the phenol sorption process [37].

Table 1. Thermodynamic parameters for phenol sorption on to magnetic $\mathrm{ZnO}$ nanotubes.

\begin{tabular}{|c|c|c|c|c|c|c|c|c|c|}
\hline $\begin{array}{l}\text { Temperature } \\
\text { (K) }\end{array}$ & $1000 / \mathrm{T}$ & $\mathrm{C}_{\mathrm{Be}}$ & $\mathrm{C}_{\mathrm{Ae}}$ & $\mathbf{K}_{\mathrm{c}}$ & $\ln K_{c}$ & $\begin{array}{c}\Delta \mathrm{G}^{0} \\
\left(\mathrm{~kJ} \cdot \mathrm{mol}^{-1}\right)\end{array}$ & $\begin{array}{c}\mathrm{E}^{0} \\
\left(\mathrm{~kJ} \cdot \mathrm{mol}^{-1}\right)\end{array}$ & $\begin{array}{c}\Delta \mathrm{H}^{0} \\
\left(\mathrm{~kJ} \cdot \mathrm{mol}^{-1}\right)\end{array}$ & $\begin{array}{c}\Delta S^{0} \\
\left(\mathrm{~J} \cdot \mathrm{mol}^{-1} \cdot \mathrm{K}^{-1}\right)\end{array}$ \\
\hline 298 & 3.356 & 8.775 & 1.225 & 7.163 & 1.969 & -4.878 & 2.501 & \multirow{5}{*}{23.495} & \multirow{5}{*}{96.027} \\
\hline 313 & 3.195 & 9.134 & 0.866 & 10.547 & 2.356 & -6.119 & 2.626 & & \\
\hline 328 & 3.049 & 9.642 & 0.358 & 26.933 & 3.293 & -8.983 & 2.750 & & \\
\hline 343 & 2.915 & 9.678 & 0.322 & 30.056 & 3.403 & -9.706 & 2.875 & & \\
\hline 358 & 2.793 & 9.709 & 0.291 & 33.364 & 3.508 & -10.44 & 3.000 & & \\
\hline
\end{tabular}

3.3.1. Equilibrium Isotherm Analysis for the Phenol Sorption Process on to Magnetic ZnO Nanotubes

The plot of $C_{e} / q_{e}$ versus $C_{e}$ (figure not investigated) shows a straight-line trend with a high correlation coefficient fraction $\left(R^{2}=0.966\right)$ [39]:

$$
\frac{\mathrm{C}_{\mathrm{e}}}{\mathrm{q}_{\mathrm{e}}}=\frac{1}{\mathrm{q}_{\mathrm{m}} \mathrm{K}}+\frac{\mathrm{C}_{\mathrm{e}}}{\mathrm{q}_{\mathrm{m}}}
$$

where $\mathrm{C}_{\mathrm{e}}$ is the equilibrium concentration of the adsorbate ions $(\mathrm{mg} / \mathrm{L}) ; \mathrm{q}_{\mathrm{e}}$ is the amount adsorbed ( $\mathrm{mg} / \mathrm{g}$ ); and $\mathrm{q}_{\mathrm{m}}$ and $\mathrm{K}$ are Langmuir constants correlated to the maximum monolayer adsorption capacity (monolayer capacity) $(\mathrm{mg} / \mathrm{g}$ ) and energy of adsorption $(\mathrm{L} / \mathrm{mg})$, respectively. Accordingly, the Langmuir isotherm model may be adequate for designating the phenol sorption process on to the synthesized magnetic $\mathrm{ZnO}$ nanotubes. The Langmuir constants $\mathrm{q}_{\mathrm{m}}$ and $\mathrm{K}$ are determined from the slope and intercept of the linear plot, respectively (Table 2).

Table 2. Isotherm parameters of the three models, Langmuir, Freundlich and Temkin, for phenol removal on to magnetic $\mathrm{ZnO}$ nanotubes.

\begin{tabular}{ccc}
\hline Isotherms & Parameters & Value \\
\hline \multirow{3}{*}{ Langmuir } & $\mathrm{q}_{\mathrm{m}}(\mathrm{mg} / \mathrm{g})$ & 20.408 \\
& $\mathrm{k}(\mathrm{L} / \mathrm{mg})$ & 0.107 \\
& $\mathrm{R}^{2}$ & 0.966 \\
\hline \multirow{3}{*}{ Freundlich } & $\mathrm{K}_{\mathrm{F}}$ & 1.122 \\
& $(\mathrm{mg} / \mathrm{g})(\mathrm{L} / \mathrm{mg})^{1 / \mathrm{n}}$ & 0.612 \\
& $1 / \mathrm{h}_{\mathrm{F}}$ & 0.978 \\
\hline \multirow{2}{*}{ Temkin } & $\mathrm{R}^{2}$ & 2.722 \\
& $\mathrm{~A}(\mathrm{~L} / \mathrm{g})$ & 3.164 \\
& $\mathrm{~B}(\mathrm{~J} / \mathrm{mol})$ & 0.923 \\
\hline
\end{tabular}

The value of the correlation coefficient $\left(R^{2}=0.966\right)$ has good linearity. The dimensionless constant separation factor $\mathrm{R}_{\mathrm{L}}$ representing the important characteristics of the Langmuir isotherm can be expressed in Equation (8):

$$
\mathrm{R}_{\mathrm{L}}=1 /\left(1+\mathrm{KC}_{0}\right)
$$


where $C_{0}(\mathrm{mg} / \mathrm{L})$ is the adsorbate initial concentration; and $\mathrm{K}(\mathrm{L} / \mathrm{mg})$ is Langmuir constant. $\mathrm{R}_{\mathrm{L}}$ indicates the shape of the isotherm which is unfavorable $\left(R_{L}>1\right)$, linear $\left(R_{L}=1\right)$, favorable $\left(0<R_{L}<1\right)$, or irreversible $\left(R_{L}=0\right)$. The $R_{L}$ value for the adsorption of phenol on to magnetic $\mathrm{ZnO}$ nanotubes is observed to be in the range 0 to 1 ; this range investigates the favorable adsorption method. These results can be explained, as the hypothesis of the Langmuir isotherm equation is based upon the monolayer coverage of adsorbate molecule over a homogeneous surface of the adsorbent material, which means that the material surface consists of similar active sites. These sites are similarly available for adsorption with equivalent adsorption energies. Consequently, a saturation point is recorded at equilibrium and no further adsorption will take place after this point. The adsorption process is supposed to take place at specific homogeneous sites on magnetic $\mathrm{ZnO}$ nanotubes and, once a phenol molecule occupies the active sites, the adsorption process finishes, allowing the prediction that the process may be chemisorption [38].

Additionally, the equilibrium sorption data were analyzed using the Freundlich linear form Equation (9), by plotting $\log \mathrm{q}_{\mathrm{e}}$ against $\log \mathrm{C}_{\mathrm{e}}$. The estimated constants $\left(\mathrm{K}_{\mathrm{F}}, \mathrm{n}_{\mathrm{F}}\right)$ of Freundlich and the correlation coefficient $\mathrm{R}^{2}$ are tabulated in Table 2.

$$
\log q_{e}=\log K_{F}+1 / n_{F} \log C_{e}
$$

where $\mathrm{K}_{\mathrm{F}}$ and $\mathrm{n}_{\mathrm{F}}$ are Freundlich constants correlated to the capacity and intensity of adsorption, respectively. The high correlation coefficient $\left(R^{2}=0.972\right)$ represents the agreement of the Freundlich equation with the experimental results of phenol sorption on to magnetic $\mathrm{ZnO}$ nanotubes. The best fit of the equilibrium data with the Freundlich isotherm assumes a heterogeneous adsorption surface with a non-uniform distribution of adsorption heat. The calculated $n_{F}$ value of 1.63 is greater than unity, showing that the phenol sorption process on to magnetic $\mathrm{ZnO}$ nanotubes was favorable. As the phenol sorption process obeys the Freundlich model, this supposes that the multi-layer sorption of phenol on to magnetic $\mathrm{ZnO}$ nanotubes allows predictions about physical phenol adsorption on to the prepared material [36].

The adsorption data for phenol on magnetic $\mathrm{ZnO}$ nanotubes were analyzed to fit the Temkin isotherm model expressed as [39]:

$$
\mathrm{q}_{\mathrm{e}}=\mathrm{B} \ln \mathrm{A}+\mathrm{B} \ln \mathrm{C}_{\mathrm{e}}
$$

where, $\mathrm{B}=\mathrm{RT} / \mathrm{b}$ is constant correlates to sorption heat $(\mathrm{J} / \mathrm{mol})$; and $\mathrm{A}$ is the Temkin isotherm constant (L/g).

The Temkin model constants and the correlation coefficient are illustrated in Table 2. Comparing the correlation coefficient of the Temkin model with those for Langmuir and Freundlich, it obvious that the equilibrium data of the phenol sorption process on to magnetic $\mathrm{ZnO}$ follows both the latter models to a great extent.

\subsubsection{Kinetic Model of Phenol Adsorption Process on to Hollow Magnetic ZnO Nanotubes}

It is necessary to ascertain the removal rate of dissolved phenol from aqueous solution using solid sorbent material in order to assess the kinetics of the adsorption process by theoretical modeling so as to control the adsorption process. This is so that the suitability of the pseudo-first-order, pseudo-second-order and Elovich models can be verified for phenol adsorption on to magnetic $\mathrm{ZnO}$ nanotubes. The best-fit of the kinetics model is designated based on the linear correlation coefficient values. The Lagergren first-order equation [40] is expressed as:

$$
\ln \left(\mathrm{q}_{\mathrm{e}}-\mathrm{q}_{\mathrm{t}}\right)=\ln \mathrm{q}_{\mathrm{e}}-\mathrm{k}_{1} \mathrm{t}
$$

where, $\mathrm{q}_{\mathrm{e}}$ and $\mathrm{q}_{\mathrm{t}}$ are the amounts of phenol ions sorbed $(\mathrm{mg} / \mathrm{g}$ ) at equilibrium and at time (min), respectively; and $\mathrm{k}_{1}(\mathrm{~min})$ is the first-order reaction rate constant. The calculated values of $\mathrm{k}_{1}, \mathrm{q}_{\mathrm{e}}$ from the equation and the correlation coefficient $\left(R^{2}\right)$ value for fitting the first-order rate model are tabulated 
in Table 3. The linearity of $\ln \left(\mathrm{q}_{\mathrm{e}}-\mathrm{q}_{\mathrm{t}}\right)$ plotting against time indicates that the phenol sorption process did not follow the first-order rate kinetic model [29]. Additionally, the calculated value of $\left(\mathrm{q}_{\text {ecal }}\right)$ obtained from the equation differs significantly from the experimentally (qeexp) measured values. This confirms that the alkaline phenol sorption process using magnetic $\mathrm{ZnO}$ nanotubes did not follow the pseudo-first-order model.

Table 3. Pseudo first-order, second-order and Elovich kinetic parameters for phenol removal on to magnetic $\mathrm{ZnO}$ nanotubes.

\begin{tabular}{ccc}
\hline Kinetic Model & Parameter & Value \\
\hline \multirow{3}{*}{ Pseudo-first-order } & $\mathrm{q}_{\exp }(\mathrm{mg} / \mathrm{g})$ & 4.388 \\
& $\mathrm{q}_{\text {theor }}(\mathrm{mg} / \mathrm{g})$ & 1.817 \\
& $\mathrm{~K}_{1}\left(\mathrm{~min}^{-1}\right)$ & 0.033 \\
& $\mathrm{R}^{2}$ & 0.872 \\
\hline \multirow{3}{*}{ Pseudo-second-order } & $\mathrm{q}_{\exp }(\mathrm{mg} / \mathrm{g})$ & 4.388 \\
& $\mathrm{q}_{\text {theor }}(\mathrm{mg} / \mathrm{g})$ & 4.405 \\
& $\mathrm{~K}_{2}(\mathrm{~g} / \mathrm{mg} \cdot \mathrm{min})$ & 0.042 \\
& $\mathrm{R}^{2}$ & 0.994 \\
\hline \multirow{3}{*}{ Elovich kinetic model } & $\mathrm{q}_{\exp }(\mathrm{mg} / \mathrm{g})$ & 4.388 \\
& $\alpha(\mathrm{mg} / \mathrm{g} \cdot \mathrm{min})$ & 4.196 \\
& $\beta(\mathrm{g} / \mathrm{mg})$ & 2.158 \\
& $\mathrm{R}^{2}$ & 0.453 \\
\hline
\end{tabular}

Furthermore, the phenol sorption kinetic data are examined using the pseudo second-order kinetic model that may be represented as:

$$
t / q_{t}=\left(1 / k_{2} q^{2}\right)+t / q
$$

where $k_{2}$ is the second-order reaction rate equilibrium constant $(\mathrm{g} / \mathrm{mg} \cdot \mathrm{min})$. The plot of $\mathrm{t} / \mathrm{q}_{\mathrm{t}}$ against time (figure not presented) shows a straight line with high correlation coefficient values, $R^{2}(>0.99)$, compared with the first-order rate model (Table 3). Furthermore, the calculated value of $\mathrm{q}_{\mathrm{e}}$ is very close to that obtained experimentally. Consequently, the second order kinetic model is more appropriate for describing the phenol sorption process on to the magnetic zinc oxide nanotubes that supposes a chemisorption process [41].

An Elovich equation is established for the multilayer adsorption, assuming that the adsorption sites increase exponentially with adsorption that may be written as:

$$
\mathrm{q}_{\mathrm{t}}=\alpha+\beta \ln \mathrm{t}
$$

where $\alpha$ signifies the initial sorption rate $(\mathrm{mg} / \mathrm{g} \cdot \mathrm{min})$ and $\beta$ is correlated to the surface coverage degree and chemisorption activation energy $(\mathrm{g} / \mathrm{mg})$. The constants $\alpha$ and $\beta$ can be calculated from the slope and intercept of the linear plot of $q_{t}$ versus $\ln t$ and is tabulated in Table 3. This indicates that the correlation coefficient of Elovich fitting is equal to 0.878 , suggesting that the sorption process cannot be explained by the Elovich model [38].

\subsection{Phenol Desorption Process}

The regeneration of the adsorbent is one of the most important factors, since it affects the overall cost of the adsorption process. Various attempts have been made previously to desorb phenol from different adsorbent materials using many elution reagents, such as hydrochloric acid, ethanol and sodium hydroxide. From all of these attempts, sodium hydroxide has been found to be the most favorable reagent for phenol desorption [42]. Consequently, phenol adsorbed on the magnetic $\mathrm{ZnO}$ nanotubes is desorbed using a $\mathrm{NaOH}$ solution at various strengths. Table 4 shows that the amount 
of phenol desorbed increases with increasing strength of $\mathrm{NaOH}$ solution. The results indicate that the solution strength of $0.2 \mathrm{~N} \mathrm{NaOH}$ is sufficient for quantitative desorption of a $68 \%$ phenol fraction from the magnetic $\mathrm{ZnO}$ nanotubes. The elution of phenol from the magnetic $\mathrm{ZnO}$ nanotubes in the presence of $0.2 \mathrm{~N} \mathrm{NaOH}$ may be attributed to the formation of a sodium salt of phenol which may facilitate desorption of phenol from the magnetic material surfaces [43]. Rengaraj et al. [44] found that approximately $0.14 \mathrm{~N} \mathrm{NaOH}$ is required for quantitative desorption of phenol from activated carbon.

Table 4. Fraction of desorbed phenol from magnetic $\mathrm{ZnO}$ nanotubes using $\mathrm{NaOH}$ solution after being saturated by $10 \mathrm{ppm}$ initial phenol solution for $90 \mathrm{~min}$ contact time (desorption contact time $=24 \mathrm{~h}$ ).

\begin{tabular}{cc}
\hline Sodium Hydroxide Concentration & Percentage Phenol Desorbed \\
\hline $0.05 \mathrm{~N}$ & 24.2 \\
$0.1 \mathrm{~N}$ & 30.7 \\
$0.15 \mathrm{~N}$ & 47.8 \\
$0.2 \mathrm{~N}$ & 68 \\
$0.25 \mathrm{~N}$ & 70 \\
$0.3 \mathrm{~N}$ & 73.55 \\
\hline
\end{tabular}

\section{Conclusions}

Hollow structured magnetic zinc oxide nanotubes were successfully synthesized using the microwave method in the presence of PVA as a stabilizing agent followed by sonic precipitation of magnetite nano-particles. The prepared material was examined using X-ray diffraction, scanning electron microscopy, transmission electron microscopy and vibrating sample magnetometer techniques to confirm its purity, nano-size and magnetic properties, respectively. Improvement in both the phenol solution temperature and material dosage has a positive impact on the percentage of phenol decontamination. Estimation of the thermodynamic parameters $\left(\Delta \mathrm{G}^{0}, \Delta \mathrm{H}^{0}, \Delta \mathrm{S}^{0}\right.$ and $\left.\mathrm{E}_{\mathrm{a}}\right)$ demonstrates the spontaneous and endothermic nature of the phenol sorption process. However, a positive value of $\Delta \mathrm{S}^{0}$ indicates increasing randomness at the solid/liquid interface during the adsorption of phenol on to magnetite $\mathrm{ZnO}$ nanotubes. On the other hand, the mathematical description of the phenol adsorption equilibrium on to magnetic zinc oxide nanotubes was tested using Langmuir, Freundlich and Temkin isotherm equations. This mathematical equilibrium modeling suggested that phenol decontamination using magnetite $\mathrm{ZnO}$ nanotubes includes both chemical and physical adsorption processes. Finally, three kinetics models comprising pseudo-first-order reaction rate, pseudo-second-order reaction rate and Elovich models were used to examine the phenol adsorption process. It was evident that the adsorption of phenol on to the magnetic zinc oxide nanotubes was described well by the pseudo-second-order reaction rate model, which allows a prediction that the studied sorption system is controlled by a chemisorption process.

Acknowledgments: This work was supported by the Egyptian Science and Technology Development fund (STDF) (Grant No. 10763). Author thanks the Deanship of Scientific Research at King Khalid University (KKU) for funding this research project Number: (R.G.P.2/2/38).

Author Contributions: Marwa F. Elkady and Hassan Shokry Hassan conceived and designed the experiments; Wael A. Amer and Eslam Salama performed the experiments; Essam Ramadan Shaaban analyzed the data; Hamed Algarni contributed reagents/materials/analysis tools; and Marwa F. Elkady and Eslam Salama wrote the paper.

Conflicts of Interest: The authors declare no conflict of interest.

\section{References}

1. Elkady, M.F.; Hassan, H.S.; Hashim, A. Immobilization of magnetic nanoparticles onto amine-modified nano-silica gel for copper ions remediation. Materials 2016, 9, 460. [CrossRef] [PubMed]

2. Elkady, M.F.; Hassan, H.S.; Salama, E. Sorption profile of phosphorus ions onto ZnO nanorods synthesized via sonic technique. J. Eng. 2016, 2016, 2308560. [CrossRef] 
3. Elkady, M.F.; Hassan, H.S.; Hamad, H. Effect of superparamagnetic nanoparticles on the physicochemical properties of nano hydroxyapatite for groundwater treatment: Adsorption mechanism of Fe(II) and Mn(II). RSC Adv. 2016, 6, 82244-82259. [CrossRef]

4. El-Aassar, M.R.; Elkady, M.F.; Hassan, H.S.; Al-Deyab, S.S. Synthesis and characterization of surface modified electrospun poly (acrylonitrile-co-styrene) nanofibers for dye decolorization. J. Taiwan Inst. Chem. Eng. 2016, 58, 274-282. [CrossRef]

5. Elkady, M.F.; Hassan, H.S.; El-Sayed, E.M. Basic Violet Decolourization Using Alginate Immobilized Nanozirconium Tungestovanadate Matrix as Cation Exchanger. J. Chem. 2015, 2015, 385741. [CrossRef]

6. Elkady, M.F.; EL-Sayed, E.; Farag, H.; Zaatout, A. Assessment of novel synthetized nanozirconium tungstovanadate as cation exchanger for lead ion decontamination. J. Nanomater. 2014, 2014, 149312. [CrossRef]

7. Villegas, L.G.C.; Mashhadi, N.; Chen, M.; Mukherjee, D.; Taylor, K.E.; Biswas, N. A Short Review of Techniques for Phenol Removal from Wastewater. Curr. Pollut. Rep. 2016, 2, 157-167. [CrossRef]

8. Dougna, A.A.; Gombert, B.; Kodom, T.; Djaneye-Boundjou, G.; Boukari, S.O.B.; Leitner, N.K.V.; Bawa, L.M. Photocatalytic removal of phenol using titanium dioxide deposited on different substrates: Effect of inorganic oxidants. J. Photochem. Photobiol. A 2015, 305, 67-77. [CrossRef]

9. Elkady, M.F.; Hassan, H.S. Invention of hollow zirconium tungesto-vanadate at nanotube morphological structure for radionuclides and heavy metal pollutants decontamination from aqueous solutions. Nanoscale Res. Lett. 2015, 10, 1-6. [CrossRef] [PubMed]

10. Martínez-Huitle, C.A.; Ferro, S. Electrochemical oxidation of organic pollutants for the wastewater treatment: Direct and indirect processes. Chem. Soc. Rev. 2006, 35, 1324-1340. [CrossRef] [PubMed]

11. Wang, Y.; Gao, B.; Yue, Q.; Wang, Y.; Yang, Z. Removal of acid and direct dye by epichlorohydrindimethylamine: Flocculation performance and floc aggregation. Bioresour. Technol. 2012, 113, 265-271. [CrossRef] [PubMed]

12. Deng, N.; Wu, F.; Luo, F.; Liu, Z. Photodegradation of dyes in aqueous solutions containing Fe(III)-oxalato complexes. Chemosphere 1997, 35, 2697-2706.

13. Liotta, L.F.; Gruttadauria, M.; DiCarlo, G.; Perrini, G.; Librando, V. Heterogeneous catalytic degradation of phenolic substrates: Catalysts activity. J. Hazard. Mater. 2009, 162, 588-606. [CrossRef] [PubMed]

14. Faria, P.C.C.; Orfao, J.J.M.; Pereira, M.F.R. Mineralization of substituted aromatic compounds by ozonation catalyzed by cerium oxide and a cerium oxide-activated carbon composite. Catal. Lett. 2009, 127, 195-203. [CrossRef]

15. El Ashtoukhy, E.S.Z. Loofa egyptiaca as a novel adsorbent for removal of direct blue dye from aqueous solution. J. Environ. Manag. 2009, 90, 2755-2761. [CrossRef] [PubMed]

16. Deniz, F.; Karaman, S. Removal of Basic Red 46 Dye from aqueous solution by pine tree leaves. Chem. Eng. J. 2011, 170, 67-74. [CrossRef]

17. Vieira, A.P.; Santana, S.A.A.; Bezerra, C.W.B.; Silva, H.A.S.; Chaves, J.A.P.; Melo, J.C.P.; Filho, E.C.S.; Airold, C. Kinetics and thermodynamics of textile dye adsorption from aqueous solutions using babassu coconut mesocarp. J. Hazard. Mater. 2009, 166, 1272-1278. [CrossRef] [PubMed]

18. Hameed, B.H.; El-Khaiary, M.I. Removal of phenol from aqueous solutions by adsorption onto activated carbon prepared from biomass material. J. Hazard. Mater. 2008, 159, 576-581. [CrossRef] [PubMed]

19. Orlando, U.S.; Okuda, T.; Nishijima, W. Chemical properties of anion exchangers prepared from waste natural materials. React. Funct. Polym. 2003, 55, 311-318. [CrossRef]

20. Gong, R.M.; Ding, Y.; Li, M.; Yang, C.; Liu, H.; Sun, Y. Utilization of powdered peanut hull as biosorbent for removal of anionic dyes from aqueous solution. Dyes Pigments 2005, 64, 187-192. [CrossRef]

21. Robinson, T.; Chandran, B.; Nigam, P. Removal of dyes from a synthetic textile dye effluent by biosorption on apple pomace and wheat straw. Water Res. 2002, 36, 2824-2830. [CrossRef]

22. Li, L.H.; Xiao, J.; Liu, P.; Yang, G.W. Super adsorption capability from amorphousization of metal oxide nanoparticles for dye removal. Sci. Rep. 2015, 5, 1-6. [CrossRef] [PubMed]

23. Hassan, H.S.; Elkady, M.F.; Hafez, E.E.; Salama, E. Novel antibacterial zinc oxide polymeric nanocomposite membrane as wound dress. Nanosci. Nanotechnol. Asia 2017, 7, 62-72. [CrossRef]

24. Lu, H.; Wang, J.; Stoller, M.; Wang, T.; Bao, Y.; Hao, H. An overview of nanomaterials for water and wastewater treatment. Adv. Mater. Sci. Eng. 2016, 2016, 4964828. [CrossRef] 
25. Lee, K.M.; Lai, C.W.; Ngai, K.S.; Juan, J.C. Recent developments of zinc oxide based photocatalyst in water treatment technology: A review. Water Res. 2016, 88, 428-448. [CrossRef] [PubMed]

26. Hasanpoor, M.; Aliofkhazraei, M.; Delavari, H. Microwave-assisted synthesis of zinc oxide nanoparticles. Procedia Mater. Sci. 2015, 11, 320-325. [CrossRef]

27. Kong, X.; Duan, Y.; Peng, P.; Qiu, C.; Wu, L.; Liu, L.; Zheng, W. A novel route to prepare ZnO nanotubes by using microwave irradiation method. Chem. Lett. 2007, 36, 428-429. [CrossRef]

28. Shaaban, E.R.; El-Hagary, M.; Moustafa, E.; Hassan, H.S.; Ismail, Y.A.M.; Ismail, M.E.; Ali, A.S. Structural, linear and nonlinear optical properties of co-doped ZnO thin films. Appl. Phys. A 2016, 122, 1-20. [CrossRef]

29. Elkady, M.F.; Hassan, H.S. Equilibrium and dynamic profiles of azo dye sorption onto innovative nano-zinc oxide biocomposite. Curr. Nanosci. 2015, 11, 805-814. [CrossRef]

30. Hassan, H.S.; Elkady, M.F.; Farghali, A.A.; Salem, A.M.S.; Abd El-Hamid, A.I. Fabrication of novel magnetic zinc oxide cellulose acetate hybrid nano-fiber to be utilized for phenol decontamination. J. Taiwan Inst. Chem. Eng. 2017, 78, 307-316. [CrossRef]

31. Nikazar, M.; Alizadeh, M.; Lalavi, R.; Rostami, M.H. The optimum conditions for synthesis of $\mathrm{Fe}_{3} \mathrm{O}_{4} / \mathrm{ZnO}$ core/shell magnetic nanoparticles for photodegradation of phenol. J. Environ. Health Sci. Eng. 2014, 12, 12-21. [CrossRef] [PubMed]

32. Nguyen, V.C. Bifunctional core-shell nanocomposite Mndoped $\mathrm{ZnO} / \mathrm{Fe}_{3} \mathrm{O}_{4}$ for photodegradation of reactive blue 198 dye. Adv. Nat. Sci. Nanosci. Nanotechnol. 2014, 5, 1-6. [CrossRef]

33. Elkady, M.F.; Hassan, H.S.; Hafez, E.E.; Fouad, A. Construction of zinc oxide into different morphological structures to be utilized as antimicrobial agent against multidrug resistant bacteria. Bioinorg. Chem. Appl. 2015, 2015, 536854. [CrossRef] [PubMed]

34. Park, J.Y.; Patel, D.; Choi, E.S.; Baek, M.J.; Chang, Y.; Kim, T.J.; Lee, G.H. Salt effects on the physical properties of magnetite nanoparticles synthesized at different $\mathrm{NaCl}$ concentrations. Colloids Surf. 2010, 367, 41-46. [CrossRef]

35. Malayeri, H.Z.; Ayati, B.; Ganjidoust, H. Photocatalytic phenol degradation by immobilized nano ZnO. Water Environ. Res. 2014, 86, 771-778. [CrossRef] [PubMed]

36. Abd El-Latif, M.; Ibrahim, A.M.; El-Kady, M.F. Adsorption equilibrium, kinetics and thermodynamics of methylene blue from aqueous solutions using biopolymer oak sawdust composite. J. Am. Sci. 2010, 6, 267-283.

37. Thinakaran, N.; Baskaralingam, P.; Pulikesi, M.; Panneerselvam, P.; Sivanesan, S. Removal of acid violet 17 from aqueous solution by adsorption on to activated carbon prepared from sunflower seed hull. J. Hazard. Mater. 2008, 151, 316-322. [CrossRef] [PubMed]

38. Parida, K.M.; Pradhan, A.C. Removal of phenolic compounds from aqueous solutions by adsorption onto manganese nodule leached residue. J. Hazard. Mater. 2010, 173, 758-764. [CrossRef] [PubMed]

39. Elkady, M.F.; El-Aassar, M.R.; Hassan, H.S. Adsorption profile of basic dye onto novel fabricated carboxylated functionalized co-polymer nanofibers. Polymers 2016, 8, 177. [CrossRef]

40. Alkaram, U.F.; Mukhlis, A.A.; Al-Dujaili, A.H. The removal of phenol from aqueous solutions by adsorption using surfactant-modified bentonite and kaolinite. J. Hazard. Mater. 2009, 169, 324-332. [CrossRef] [PubMed]

41. Özer, A.; Dursun, G. Removal of methylene blue from aqueous solution by dehydrated wheat bran carbon. J. Hazard. Mater. 2007, 146, 262-269. [CrossRef] [PubMed]

42. Ozkaya, B. Adsorption and desorption of phenol on activated carbon and a comparison of isotherm models. J. Hazard. Mater. 2007, 129, 158-163. [CrossRef] [PubMed]

43. Qadeer, R.; Rehan, A.H. A study of the adsorption of phenol by activated carbon from aqueous solutions. Turk. J. Chem. 2002, 26, 357-361.

44. Rengaraj, S.; Moon, S.; Sivabalan, R.; Arabindoo, B.; Murugesan, V. Removal of phenol from aqueous solution and resin manufacturing industry wastewater using an agricultural waste: Rubber seed coat. J. Hazard. Mater. 2002, 89, 185-196. [CrossRef]

(c) 2017 by the authors. Licensee MDPI, Basel, Switzerland. This article is an open access article distributed under the terms and conditions of the Creative Commons Attribution (CC BY) license (http:/ / creativecommons.org/licenses/by/4.0/). 